\title{
Phylogenetic analysis of the genera Bradyrhizobium, Mesorhizobium, Rhizobium and Sinorhizobium on the basis of 16S rRNA gene and internally transcribed spacer region sequences
}

Correspondence Soon-Wo Kwon swkwon@rda.go.kr

\author{
Soon-Wo Kwon, ${ }^{1}$ Jin-Young Park, ${ }^{1}$ Jong-Shik Kim, ${ }^{2}$ Jun-Won Kang, ${ }^{3}$ \\ Yang-Hee Cho, ${ }^{1}$ Chun-Keun Lim, ${ }^{4}$ Matthew A. Parker ${ }^{5}$ and Gil-Bok Lee ${ }^{1}$ \\ ${ }^{1}$ Korean Agricultural Culture Collection (KACC), Genetic Resources Division, National Institute \\ of Agricultural Biotechnology, Rural Development Administration (RDA), Suwon 441-707, \\ Korea \\ ${ }^{2}$ Department of Environmental Sciences, University of California, Riverside, CA 92521-0424, \\ USA \\ ${ }^{3}$ Department of Forest Resources, College of Agriculture and Life Sciences, Seoul National \\ University, Suwon 441-744, Korea \\ ${ }^{4}$ College of Agriculture and Life Sciences, Kangwon National University, Chunchon 200-701, \\ Korea \\ ${ }^{5}$ Department of Biological Sciences, State University of New York, Binghamton, \\ NY 13902-6000, USA
}

\begin{abstract}
A total of 128 strains was isolated from more than 23 legume hosts in Korea. Phylogenetic relationships between these Korean isolates and reference strains of the genera Bradyrhizobium, Mesorhizobium, Rhizobium and Sinorhizobium were analysed using their 16S rRNA gene and internally transcribed spacer (ITS) region sequences. Among the Bradyrhizobium strains, dendrograms based on both the 16S rRNA gene and ITS region sequences produced two main groups. The ITS tree yielded at least two new clusters that were discernable from the seven previously delineated genospecies. Large discrepancies were revealed between phylogenetic dendrograms based on $16 \mathrm{~S}$ rRNA gene and ITS region sequences for members of the genus Rhizobium, reflecting their taxonomic heterogeneity. The amalgamation of Rhizobium and former members of Agrobacterium was confirmed using the 16S rRNA tree. Phylogenetic analysis of ITS region sequences showed that the Rhizobium giardinii clade (group II) and the Rhizobium radiobacter/Rhizobium rubi clade (group III) could be tentatively recognized as groups that are separable from the core group (group I), which includes Rhizobium leguminosarum. Dendrograms based on the 16S rRNA gene and ITS region sequences of Mesorhizobium strains were highly conflicting due to the poor taxonomic resolution of the 16S rRNA gene sequences and the low confidence in the ITS dendrogram. Several Korean isolates within the genus Mesorhizobium are thought to represent novel taxa when considering their relatively low ITS region sequence similarities $(<80 \%)$ to the reference strains.
\end{abstract}

Published online ahead of print on 10 September 2004 as DOI 10.1099/ijs.0.63097-0.

Abbreviation: ITS, internally transcribed spacer.

The GenBank/EMBL/DDBJ accession numbers for the 16S rRNA gene and ITS sequences reported in this paper are AF345254AF345271, AF345273-AF345289, AF508136-AF508141, AF508143-AF508146, AF508148, AF509909-AF509921, AF509923-AF509932, AF510346-AF510369, AF510371, AF510372, AF510374-AF510388, AF510578-AF510635, AF510881-AF510887, AF510890-AF510927, AF511490AF511506, AF511543-AF511558, AF517932, AF517933, AF541973 and AF541974.

\section{INTRODUCTION}

Some genera within the $\alpha$-Proteobacteria are associated with plants, inducing the formation of nitrogen-fixing nodules on the roots and stems of leguminous plants or causing gall disease and root hair disease. According to Bergey's Manual of Systematic Bacteriology, the rhizobia and agrobacteria were classified into four genera (Rhizobium, Bradyrhizobium, Agrobacterium and Phyllobacterium) within the family Rhizobiaceae (Jordan, 1984). Since then, rhizobial and agrobacterial taxa have been added to and revised at the genus 
and species levels. The genus Sinorhizobium was proposed for a group of fast-growing, nodule-forming, soybean rhizobia, Rhizobium fredii (Chen et al., 1988), and this was later confirmed by de Lajudie et al. (1994). Jarvis et al. (1997) created a new genus, Mesorhizobium, for Rhizobium loti, Rhizobium huakuii, Rhizobium ciceri, Rhizobium mediterraneum and Rhizobium tianshanense. Allorhizobium undicola was the name given to nitrogen-fixing strains that nodulated Neptunia natans in Senegal (de Lajudie et al., 1998). Also, agrobacteria were classified as Agrobacterium tumefaciens, Agrobacterium radiobacter, Agrobacterium rhizogenes, Agrobacterium rubi and Agrobacterium vitis on the basis of plasmid-borne phytopathological traits. Most recently, species belonging to the genera Allorhizobium and Agrobacterium have been reclassified in the genus Rhizobium (Young et al., 2001). An overview of all members of these genera is available (http://www.bacterio.cict.fr/).

Rhizobium, Bradyrhizobium, Mesorhizobium, Sinorhizobium and the former Agrobacterium were traditionally classified on the basis of phenotypic characteristics such as nodulation, and pathogenic and physiological properties. However, nodulation and pathogenic properties have become less important in the taxonomic evaluation of these genera. Recently, high sequence variation in the internally transcribed spacer (ITS) region has been shown to be more informative for taxonomic evaluation of Bradyrhizobium strains (van Berkum \& Fuhrmann, 2000; Willems et al., 2001b).

In this study, rhizobial strains were isolated from root nodules of several legume hosts in Korea. Their ITS regions and $16 \mathrm{~S}$ rRNA genes were sequenced and compared with those of reference strains. Phylogenetic analysis of these sequences was performed to compare the dendrograms generated from these two types of sequences and to evaluate the use of the ITS region as a taxonomic marker.

\section{METHODS}

Bacterial strains and media. The bacterial strains used in this study are listed in Table 1. All strains were grown on yeast extractmannitol (YM) agar (Vincent, 1970) or nutrient broth ( $0.5 \%$ peptone, $0 \cdot 5 \%$ meat extract, $\mathrm{pH} 7 \cdot 0)$ at $30^{\circ} \mathrm{C}$. Strains were preserved using two methods: deep-freezing with $15 \%$ glycerol and freezedrying with $15 \%$ skimmed milk.

PCR amplification of the 16S rRNA gene and ITS region. The 16S rRNA gene was amplified using universal primers fD1 and rP2 (Weisburg et al., 1991). The ITS region was amplified using primers R16-1 (5'-CTTGTACACACCGCCCGTCA-3') and R23-3R (5'-GGTACTTAGATGTTTCAGTTC-3'), which were redesigned from the primers of Nakagawa et al. (1994). Primers R16-1 and R23-3R were located at positions 1389-1408 of the 16S rRNA gene and at 189-209 of the 23S rRNA gene sequence of Escherichia coli, respectively (GenBank accession no. J01695) (Brosius et al., 1978). Each PCR mixture contained the following: 20 pmol each primer, $200 \mu \mathrm{M}$ dNTPs (Promega), 2.5 U Taq DNA polymerase (Promega), approximately $50 \mathrm{ng}$ genomic DNA and Taq polymerase buffer in a final reaction volume of $50 \mu \mathrm{l}$. The DNA thermal cycler (PerkinElmer) used for PCR amplification was programmed as follows: an
Table 1. Bacterial strains isolated from legume hosts in Korea

For each strain, the generic position was determined on the basis of $16 \mathrm{~S}$ rRNA gene and ITS sequence analysis.

\begin{tabular}{|lll|}
\hline Isolate(s) & \multicolumn{1}{|c|}{ Genus } & $\begin{array}{c}\text { Legume plant from which } \\
\text { strain(s) were isolated }\end{array}$ \\
\hline Aei-1 & Bradyrhizobium & Aeschynomene indica \\
Aei-2 & Mesorhizobium & Aeschynomene indica \\
Aei-3-Aei-6 & Rhizobium & Aeschynomene indica \\
Amf-1-Amf-5 & Mesorhizobium & Amorpha fruticosa \\
Crj-1, Crj-2 & Bradyrhizobium & Crotalaria juncia \\
Crj-3, Crj-4 & Rhizobium & Crotalaria juncia \\
Glm-1-Glm-8 & Bradyrhizobium & Glycine max \\
Glm-9-Glm-15 & Rhizobium & Glycine max \\
Gls-1 & Bradyrhizobium & Glycine soja \\
Gls-2-Gls-5 & Rhizobium & Glycine soja \\
Kusp-1 & Rhizobium & Kummerowia stipulacea \\
Kus-1-Kus-6 & Bradyrhizobium & Kummerowia striata \\
Kus-7, Kus-8 & Rhizobium & Kummerowia striata \\
Leb-1-Leb-4 & Mesorhizobium & Lespedeza bicolor \\
Leb-5-Leb-14 & Bradyrhizobium & Lespedeza bicolor \\
Leb-15 & Rhizobium & Lespedeza bicolor \\
Loc-1 & Mesorhizobium & Lotus corniculatus \\
Mes-1 & Bradyrhizobium & Medicago sativa \\
Mes-2 & Sinorhizobium & Medicago sativa \\
Pha-1-Pha-10 & Bradyrhizobium & Phaseolus angularis \\
Phr-1-Phr-7 & Bradyrhizobium & Phaseolus radiatus \\
Phr-8, Phr-9 & Rhizobium & Phaseolus radiatus \\
Pis-1 & Rhizobium & Pisum sativum \\
Put-1 & Bradyrhizobium & Pueraria thunbergiana \\
Put-2, Put-3 & Mesorhizobium & Pueraria thunbergiana \\
Rop-1-Rop-4 & Mesorhizobium & Robinia pseudoacacia \\
Trp-1-Trp-6 & Rhizobium & Trifolium pratense \\
Trr-1-Trr-9 & Rhizobium & Trifolium repens \\
Vif-1 & Rhizobium & Vicia faba \\
Viv-1 & Bradyrhizobium & Vicia villosa \\
Vga-1 & Vigna angularis \\
Vgn-1-Vgn-3 & Bradyrizobium & Vigna nakashimae \\
Vgn-4, Vgn-5 & Mesorhizobium & Vigna nakashimae \\
Vgs-1-Vgs-4, & Bradyrhizobium & Vigna sinensis \\
Vgs-6-Vgs-9 & & Not known \\
Vgs-5, Vgs-10, & Rhizobium & Not known \\
\hline
\end{tabular}

initial extensive denaturation step at $94^{\circ} \mathrm{C}$ for $5 \mathrm{~min}$; 35 cycles of $94^{\circ} \mathrm{C}$ for $1 \mathrm{~min}, 58^{\circ} \mathrm{C}$ for $1 \mathrm{~min}$ and $72^{\circ} \mathrm{C}$ for $2 \mathrm{~min}$; and a final extension step at $72^{\circ} \mathrm{C}$ for $10 \mathrm{~min}$.

Cloning and sequencing. PCR products were electrophoresed on $1.5 \%$ agarose gel. In the ITS region, one or two bands from each of the strains were observed. Each band was eluted and purified with a QIAquick gel extraction kit (Qiagene). Purified DNAs were ligated into pGEM-T easy vector (Promega) and ligated plasmids were then 
used to transform Escherichia coli $\mathrm{DH} 5 \alpha \mathrm{F}^{\prime}$ cells (Sambrook et al., 1989). Nucleotide sequences were determined with an Applied Biosystems 377 sequencer. Sequencing of the ITS region was conducted with three primers, R16-1, R23-3R and ILEF (5'-GTAGCTCAGTTGGTTAGAGC-3'). ILEF was designed from a conserved region (tRNA ${ }^{\text {Ile }}$ coding region) within the ITS region.

Phylogenetic analysis. Nucleotide sequences were aligned using the program MEGALIGN (DNASTAR). An evolutionary distance matrix was generated as described by Jukes \& Cantor (1969). An evolutionary tree for the datasets was inferred by the neighbourjoining method of Saitou \& Nei (1987) using the neighbour-joining program of MEGA2 (http://www.megasoftware.net). The stability of relationships was assessed by performing bootstrap analysis of the neighbour-joining data based on 1000 resamplings.

\section{RESULTS AND DISCUSSION}

\section{5 rRNA gene and ITS region sequence determination}

A total of 128 bacterial strains was isolated from more than 23 legume hosts in Korea (Table 1). Phylogenetic analysis was carried out using $16 \mathrm{~S}$ rRNA gene sequences of about $1450 \mathrm{nt}$ from all strains used in this study, corresponding to nt 50-1501 of the Escherichia coli 16S rRNA gene sequence (Brosius et al., 1978). Most of the strains produced one band in PCR amplification of the ITS region. However, six strains (Mesorhizobium mediterraneum USDA $3392^{\mathrm{T}}$, Rhizobium gallicum R602sp ${ }^{\mathrm{T}}$, Rhizobium rubi DSM $6772^{\mathrm{T}}$, Sinorhizobium kostiense LMG $19227^{\mathrm{T}}$, Leb-2 and Glm-15) produced two bands. The sequence similarities between two clones of the same strain ranged from $77 \%$ (two clones of S. kostiense LMG $19227^{\mathrm{T}}$ ) to $98 \%$ (two clones of R. gallicum R602sp ${ }^{\mathrm{T}}$ ) and all these sequences were included in the phylogenetic analysis. Phylogenetic analysis of these ITS clones revealed that each pair of ITS clones for these strains, except for Glm15 , whose two ITS clones were positioned in separate clades, were closely related (Figs 1 and 3).

Although, in general, the high sequence variation of the ITS region allows discrimination between closely related strains, the presence of multiple types of ITS region makes interpretation of phylogenetic relationships difficult (Chun et al., 1999; Gürtler \& Stanisich, 1996). This study showed that most rhizobial strains contained one type of ITS region sequence, suggesting that this region may be useful as a marker for phylogenetic analysis. For phylogenetic analysis of ITS region sequences, the full-length ITS region with about 10 nt of the $3^{\prime}$-terminal region of the 16S rRNA gene and about $40 \mathrm{nt}$ of the $5^{\prime}$-terminal region of the $23 \mathrm{~S}$ rRNA gene was used. All ITS region sequences analysed in this study varied from 751 to $1236 \mathrm{nt}$ and contained two deduced tRNA genes, tRNA ${ }^{\text {Ile }}$ and tRNA ${ }^{\text {Ala }}$. The ILEF primer for internal sequencing of the ITS regions was designed from the conserved tRNA ${ }^{\text {Ile }}$ region. Variable sequences within the ITS region were interspersed throughout the entire region, except for the two tRNA sequences. The ITS regions for all strains revealed high sequence variation $(24-100 \%)$. To simplify the tree topology, strains with high sequence similarities, i.e. $>99 \cdot 8 \%$ (16S rRNA gene) and $>99 \cdot 7 \%$ (ITS region), were grouped into boxes at the same position in our phylogenetic trees (Figs 1, 2 and 3).

\section{Phylogenetic analysis of the Bradyrhizobium group}

For 16S rRNA gene sequence analysis of the Bradyrhizobium group, a total of 73 strains, including four type strains, 60 Korean isolates and nine strains of van Berkum \& Fuhrmann (2000), was used. The ITS region sequence analysis was conducted with a total of 79 strains, including three type strains, 60 Korean isolates, nine strains of van Berkum \& Fuhrmann (2000) and seven strains of Willems et al. (2001b). The $16 \mathrm{~S}$ rRNA gene sequence similarities among the strains were more than $93.3 \%$ and the ITS region sequence similarities were more than $44 \cdot 4 \%$. Both trees produced two main groups: group I, including Bradyrhizobium elkanii strains, and group II, including Bradyrhizobium japonicum and Bradyrhizobium liaoningense strains (Fig. 1a, b). According to the $16 \mathrm{~S}$ rRNA tree, group I was divided into two subgroups (groups Ia and Ib) (Fig. 1a). Group Ia consisted of B. elkanii strains, including B. elkanii USDA $76^{\mathrm{T}}$, and 11 Korean strains. Group Ib included only Korean strains (39 strains) isolated from different legume hosts. The phylogenetic positions of ten Korean isolates and strains of B. japonicum, B. liaoningense and Bradyrhizobium yuanmingense, which were clustered into group II, were not clear due to low bootstrap values (Fig. 1a). Based on phylogenetic analysis of the ITS region sequences, three groups with high bootstrap values were identified (Fig. 1b). Within group I, group Ia included 41 strains, all of which, except for LMG 8293, were isolated from Korean legume hosts. Among them, three strains (LMG 8293, Mes-1 and Vga-1) clustered independently. Group Ib included four B. elkanii strains, LMG 10676 and nine Korean isolates. Within group II, group IIa was composed of four B. japonicum strains (including LMG $6138^{\mathrm{T}}$ ), B. liaoningense LMG $18230^{\mathrm{T}}$ and four Korean isolates, and group IIb included four B. japonicum strains, LMG 11950, LMG 10697 and six Korean isolates. Group III was composed of two strains (LMG 15404-c4 and LMG 10300). The members of subclusters (groups Ia and Ib) within group I of the 16S rRNA tree were firmly reflected in those of subclusters (groups Ia and Ib) within group I of the ITS tree, except for a new branch of LMG 8293, Vga-1 and Mes-1 that was not recognized in the $16 \mathrm{~S}$ rRNA tree (Fig. 1a, b). Two branches (groups IIa and IIb) of group II, which were supported by relatively high bootstrap values, were determined in the ITS tree; this branching pattern was not evident in the $16 \mathrm{~S}$ rRNA tree.

van Berkum \& Fuhrmann (2000) conducted a phylogenetic study using the ITS region sequences of Bradyrhizobium strains isolated from soybean. Willems et al. (2001b) studied extensively the genus Bradyrhizobium on the basis of 16S rRNA gene and ITS sequences, amplified fragment length polymorphisms and DNA-DNA hybridization. 
(a)
B. eikanii USDA 46 (AF208516)
- B. elkanii USDA 76' (U35000)

- Gls-1 (AF510588)

- Vga-1 (AF510589)

$64-$ Glm-4 (AF510578)

- Vgnn-3 (AF510587) Glm-3 (AF510635), Mes-1 (AF510590),

$98)-\mathrm{Phr}-\mathrm{AA}$

Pha-10 (AF51062)
Vgs-8 (AF510619)

B. elkanii USDA 31 (AF208512)

B. elkanii USDA 94 (AF208518)

Phr-5 (AF510623)

Pha-1 (AF510604)

- Pha-7 (AF510614)

- Phr-2 (AF510609)

Leb-6 (AF508148)

Leb-10 (AF510597)

-Phr-1 (AF510601)

-GIm-2 (AF508137)

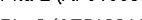

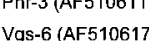

GIm-5 (AF510579)

63 - $v$ gs -9 (AF510620)

B. japonicum DSM 30131 (X87272)

$72-G \mid m-8$ (AF510582), NK-3 (AF510600)

84-Kus-6 (AF510593)

22 B. japonicum USDA 62 (AF208517)

44 Leb-14 (AF510599)

77 B. japonicum USDA 124 (AF208505), GIm-7 (AF510581)

98 Crj-2 (AF510591)

Kus-5 (AF510592)

B. japonicum USDA 38 (AF208514)

- B. japonicum USDA 4 (AF208515)

B. japonicum USDA 127 (AF208508)

B. yuanmingense CCBAU 10071T (AF193818)

- GIm-6 (AF510580)

B. japonicum USDA 135 (AF208511)

B. Haoningense LMG 18230' (AJ250813)

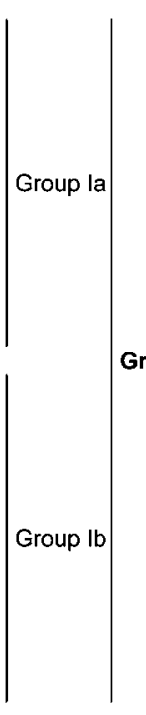

Group I

(AF508140), Cri-1 (AF508146), GIm-1 (AF508136), (AF508138), Leb-5 (AF510594), Leb-7 (AF510595), (AF508145), Leb-9 (AF508144), Leb-11 (AF508143). (AF510622), Pha-9 (AF510616), Put-1 (AF510584), (AF510602), Vgs-2 (AF510603), Vgs-3 (AF510608)

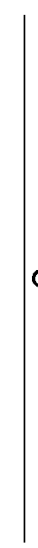

Group II

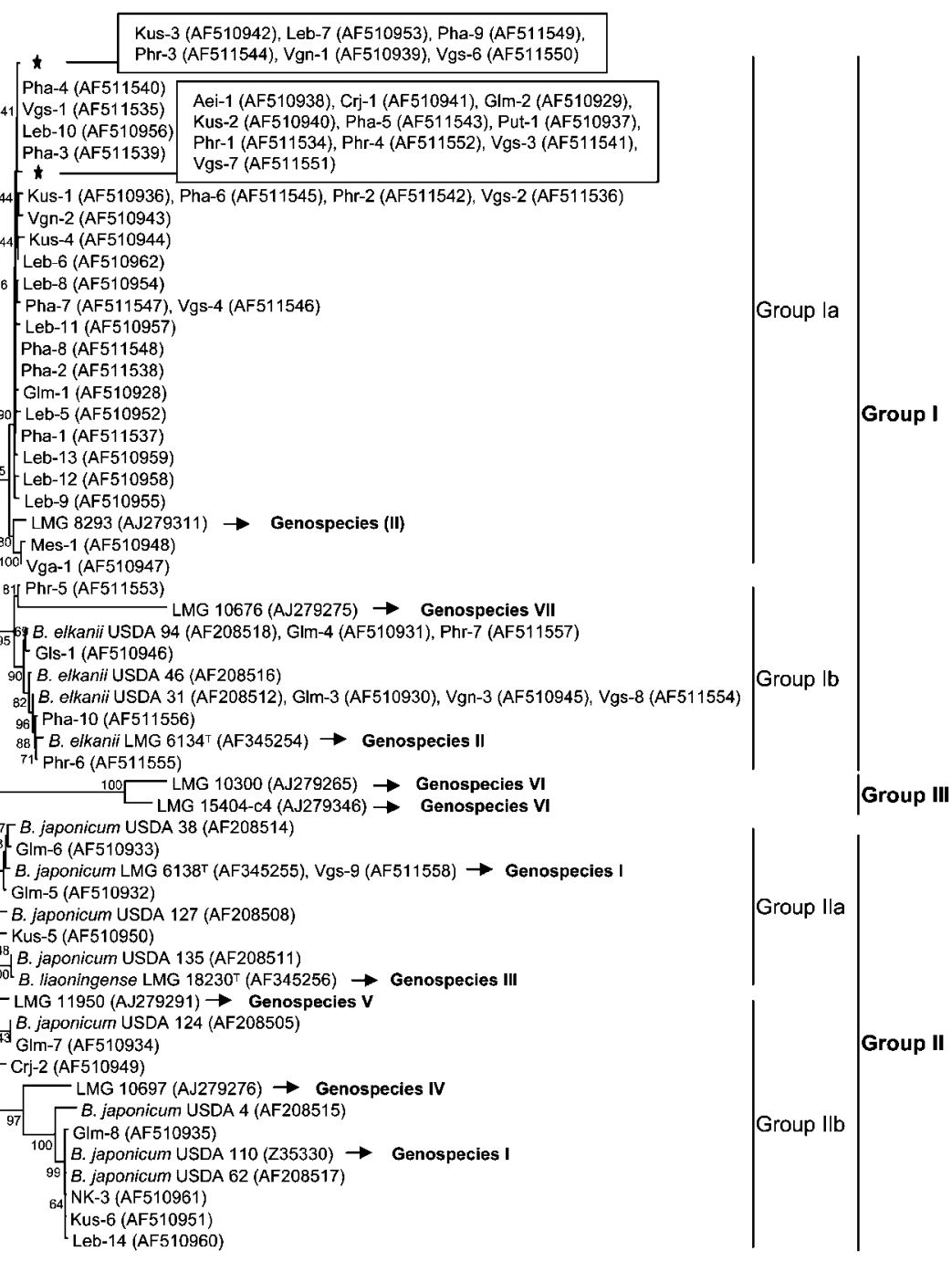

Fig. 1. Phylogenetic trees based on the $16 \mathrm{~S}$ rRNA gene (a) and ITS region sequences (b) for the genus Bradyrhizobium and related strains. The branching pattern was produced by the neighbour-joining method. Numbers at nodes indicate levels of bootstrap support based on neighbour-joining analysis of 1000 resampled datasets. Bootstrap values below $40 \%$ are not shown. Genospecies are noted according to Willems et al. (2001b). 


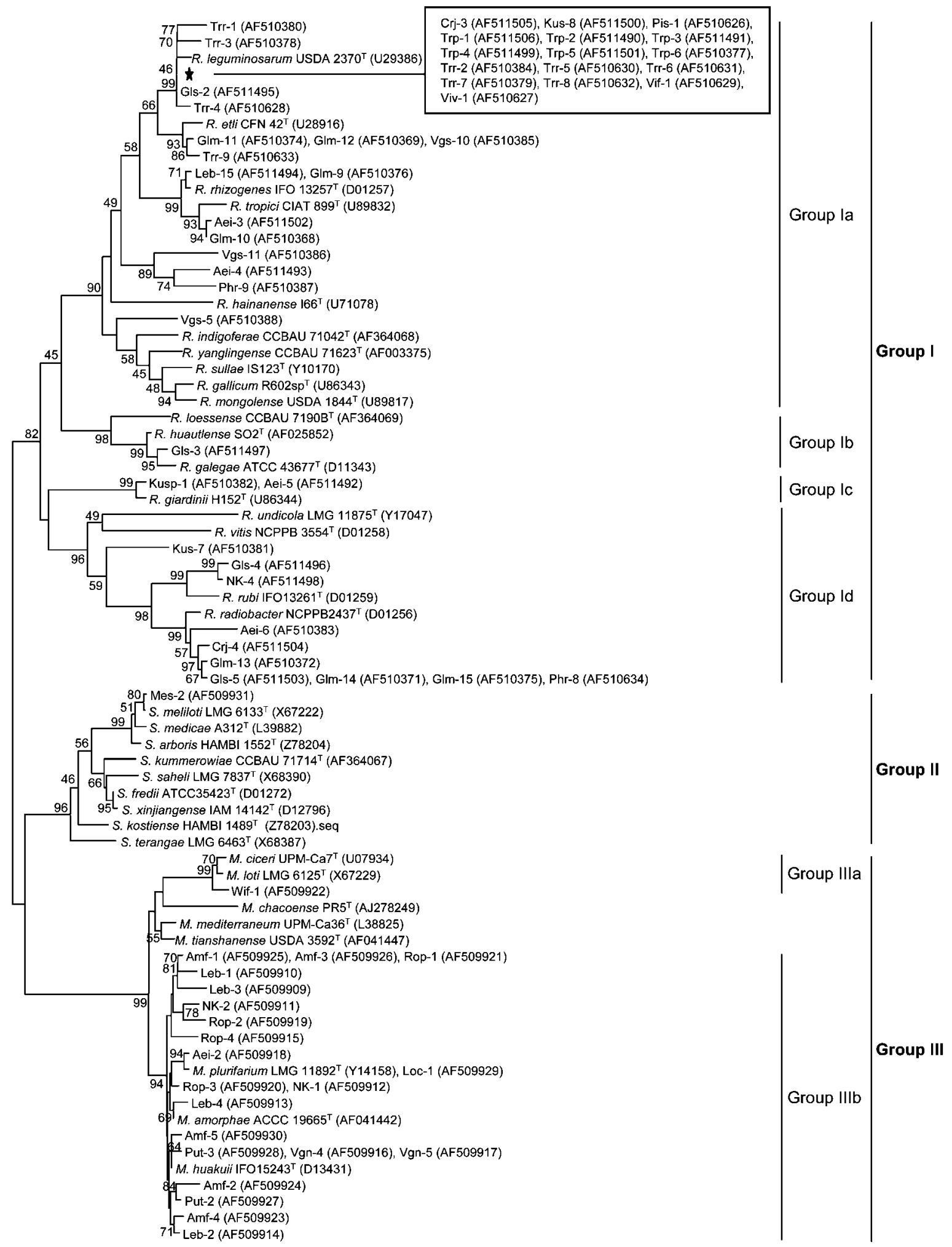

Fig. 2. Phylogenetic tree based on the $16 \mathrm{~S}$ rRNA gene for the genera Mesorhizobium, Rhizobium and Sinorhizobium and related strains. The branching pattern was produced by the neighbour-joining method. Numbers at nodes indicate levels of bootstrap support based on neighbour-joining analysis of 1000 resampled datasets. Bootstrap values below $40 \%$ are not shown. 
(a)
99. R. leguminosarum LMG 14904 (AF345271) Trp-4 (AF510911) 90 Trp-3 (AF510908)

97 Trp-5 (AF510912)

55 Trp-2 (AF510907)

Trr-5 (AF510894)

$45{ }_{100}$ Gim-11 (AF510883)

98 Gls-3 (AF510920)

R. galegae LMG 6214 (AF345265)

- Kus-7 (AF510921)

$18254^{\top}$ (AF345270)

R. gallicum R 602T 1 (AF345267)

R. mongolense USDA 1844T (AF345273)

- Vgs-10 (AF510899)

G Glm-12 (AF510884)

Trr-3 (AF510910), Trp-1 (AF510906)



\begin{tabular}{ll} 
68 Gls-2 (AF510909) & Trr-1 (AF510905), Trr-2 (AF510903), \\
\hline Vif-1 (AF510893), Viv-1 (AF510891)
\end{tabular}

R. eti LMG 17827 (AF541974)

Trr-8 (AF510896)

100 Trr-6 (AF510895)

$48 \quad$ Aei-4 (AF510917)

Phr-9 (AF510901)

${ }_{99} \mathrm{~L}$ Vgs-11 (AF510900)

56 ${ }^{-}$R. undicola LMG 11875 (AF345280)

100
$\square-$ Gim-9 (AF510881)
$\square$ Leb-15 (AF510926)

$R$. rizogenes DSM 30148 (AF345275)

R8 Aeinanense USDA 3588 (AF345269)

${ }_{90}[$ Glm-10 (AF510882)

Vgs-5 (AF510902)

98 100 Ael-5 (AF510919)

Kusp-1 (AF510918)
R. giardinii H152 (AF345268)
52 [ Glm-15 clone 2 (AF517933)

95. Glm-15 clone 2 (AF51)

R. radiobacter DSMZ 30205 (AF345274)

${ }_{100}$ R. radiobacter LMG 140' (AF541973)

55- Aei 6 (AF510925)

79 L Ael6 (AF510925)

Glm-15 clone 1 (AF510887)

100 [ Gls-4 (AF510922)

${ }_{78}^{84}\left[\begin{array}{l}\text { R. rubi DSM 6772' clone } 1 \text { (AF345276) } \\ \text { R. rubi DSM 6772' clone } 2 \text { (AF345277) }\end{array}\right.$ (b) $100 \quad 99$ Amf-5 (AF510349), Put-3 (AF510353) NK-2 (AF510358)

\section{Group I}

70 Leb-1 (AF510356)

$93-V$ An-4 (AF510361)

- Rop-1 (AF510366)
$46[$ [Leb-2 clone 1 (AF517932), Amf-4 (AF510348)
(AF51034)
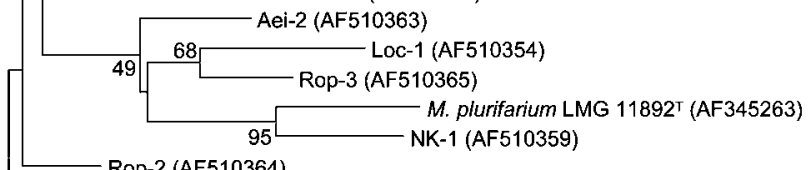
Rop-2 (AF510364)

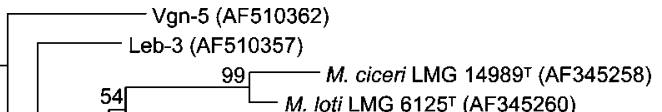

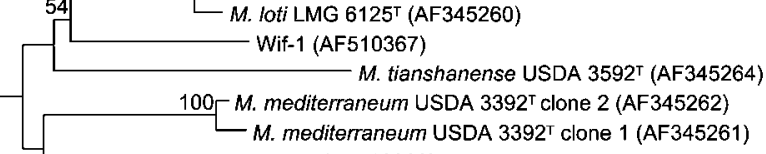
Rop-4 (AF510360)
eb-4 (AF510355)

$84 \longrightarrow$ Leb-4 (AF510355)

00 M. amorphae LMG $18977^{\top}$ (AF345257)

Group II

Group III

Fig. 3. Phylogenetic trees based on ITS region sequences for the genus Rhizobium and related strains (a) and the genus Mesorhizobium and related strains (b). For further details see the legend to Fig. 2. 
Using DNA-DNA hybridization data and ITS region sequence grouping of the Bradyrhizobium strains from several host plants, mainly Glycine max, Aeschynomene species and Faidherbia albida, seven genospecies were delineated (Willems et al., 2001b). A subsequent DNADNA hybridization study revealed four more genospecies (Willems et al., 2001c). Our ITS region sequence analysis, including representative strains of van Berkum \& Fuhrmann (2000) and Willems et al. (2001b), yielded more than two new clusters discernable from the seven groups of Willems et al. (2001b) (Fig. 1b). One distinct cluster consisted of only Korean isolates from various host plants within group Ia. The other cluster was composed of three strains (LMG 8293, Vga-1 and Mes-1) within group Ia. Although, according to Willems et al. (2001b), LMG 8293 was supposed to be related to genospecies II, which was represented by $B$. elkanii LMG $6134^{\mathrm{T}}$, our results showed that this strain formed an independent cluster with Vga-1 and Mes-1. Furthermore, the ITS region sequences of two strains (LMG 15404-c4 and LMG 10300), which were classified as genospecies VI of Willems et al. (2001a), formed a distinct cluster separable from known species and the Korean isolates. The close relationship between the type strains of $B$. japonicum and B. liaoningense was confirmed by high sequence similarities (16S rRNA gene sequence similarity of $99.8 \%$ and ITS region sequence similarity of $88.2 \%$ ) and a high DNA-DNA hybridization value (56\%) (Willems et al., 2001a, b).

\section{Phylogenetic analysis of the Rhizobium group}

For $16 \mathrm{~S}$ rRNA gene sequence analysis, the type strains of 18 Rhizobium species and 45 Korean isolates were included. For the ITS region sequence analysis, 45 Korean isolates and 15 reference strains were used. Among the strains analysed, the 16S rRNA gene sequence similarities were shown to be above $89 \cdot 4 \%$ and the ITS region sequence similarities were more than $31 \cdot 4 \%$. The $16 \mathrm{~S}$ rRNA gene sequences of members of the genus Rhizobium (group I) formed one large cluster separable from the Mesorhizobium (group III) and Sinorhizobium (group II) groups (Fig. 2). Each of these main groups comprised subclusters that were supported by high bootstrap values. Within group I, four subgroups (groups Ia-Id) were produced. Thirty-two Korean isolates formed one large cluster with several Rhizobium species, including Rhizobium leguminosarum USDA $2370^{\mathrm{T}}$ and Rhizobium etli CFN $42^{\mathrm{T}}$. Gls-3 clustered in group $\mathrm{Ib}$ with Rhizobium galegae ATCC $43677^{\mathrm{T}}$, Rhizobium huautlense $\mathrm{SO} 2^{\mathrm{T}}$ and Rhizobium loessense CCBAU $7190 \mathrm{~B}^{\mathrm{T}}$. Group Ic comprised two Korean isolates (Kusp-1 and Aei-5) and Rhizobium giardinii $\mathrm{H}_{152}{ }^{\mathrm{T}}$. Ten Korean isolates were grouped into group Id with Rhizobium radiobacter NCPPB $2437^{\mathrm{T}}$, Rhizobium rubi IFO $13261^{\mathrm{T}}$, Rhizobium vitis $\mathrm{NCPPB} 3554^{\mathrm{T}}$ and Rhizobium undicola LMG $11875^{\mathrm{T}}$.

The dendrogram generated from the ITS region sequences of these Rhizobium strains and Korean isolates revealed tree topologies comparable to those of the 16S rRNA dendrogram and produced three groups (I, II and III), which were supported by high bootstrap values (Fig. 3a). Group I formed a large complex, including all the strains of groups Ia and $\mathrm{Ib}$ of the 16S rRNA tree and three strains ( $R$. undicola LMG $11875^{\mathrm{T}}, R$. vitis LMG $8750^{\mathrm{T}}$ and Kus-7) that were classified in group Id of the 16S rRNA tree. However, the phylogenetic relationships among the strains of group I on the basis of the ITS tree could not be clarified due to low bootstrap values. Group II of the ITS tree was composed of R. giardinii $\mathrm{H} 152^{\mathrm{T}}$, Aei-5 and Kusp-1, which were found in group Ic of the $16 \mathrm{~S}$ rRNA tree. The members of group III of the ITS tree were identical to those of group Id of the $16 \mathrm{~S}$ rRNA tree, except for $R$. undicola LMG $11875^{\mathrm{T}}$, R. vitis LMG $8750^{\mathrm{T}}$ and Kus-7 (Figs 2 and 3a).

The taxonomy of the genus Rhizobium remains controversial and, recently, Young et al. (2001) suggested that the former genus Agrobacterium be combined with Rhizobium based mainly on phylogenetic analysis of the 16S rRNA gene sequences without prejudice to phenotypic characters such as pathogenicity. In the phylogenetic trees based on $16 \mathrm{~S}$ rRNA gene and ITS sequences, the Rhizobium species, including the Korean isolates, could be divided into several groups. Three major groups (I, II and III) in the ITS tree were supported by high bootstrap values and could be tentatively recognized as individual branches partially supported by the 16S rRNA tree (Fig. 2 and 3a). It could thus be suggested that the former Rhizobium and Agrobacterium be reclassified into more than two genera. However, such reclassification also might not be fully supported because of the presence of several peripheral groups and the discrepancy between the 16S rRNA and ITS trees.

\section{Phylogenetic analysis of the Mesorhizobium and Sinorhizobium groups}

For Mesorhizobium and related strains, the 16S rRNA tree was constructed for eight type strains and 22 related Korean strains and the ITS tree for 22 Korean isolates and seven type strains. Whereas the sequence similarities of the $16 \mathrm{~S}$ rRNA gene were above $97 \cdot 2 \%$, the ITS region sequence similarities were above $49 \cdot 2 \%$. The $16 \mathrm{~S}$ rRNA dendrogram grouped all Mesorhizobium and related strains into one cluster, group III (Fig. 2). Within group III, Wif-1 formed group IIIa with Mesorhizobium ciceri $\mathrm{UPM}-\mathrm{Ca}^{\mathrm{T}}$ and Mesorhizobium loti LMG $6125^{\mathrm{T}}$. Twenty-one Korean isolates clustered with Mesorhizobium plurifarium LMG $11892^{\mathrm{T}}$, Mesorhizobium amorphae ACCC $19665^{\mathrm{T}}$ and Mesorhizobium huakuii IFO $15243^{\mathrm{T}}$, forming group IIIb. The ITS tree of the Mesorhizobium and related strains resolved them into clearer branches than the 16S rRNA gene tree, but showed large disparities with the 16S rRNA tree (Fig. 3b). Due to the low ITS region sequence similarities (less than $80 \%$ ) to reference strains, most of the Korean isolates, except for Amf-5, Put-3 and Leb-4, could not be placed into any known species, suggesting the presence of several novel taxonomic units. Characteristically, the high degree of relatedness $(92 \cdot 8 \%)$ of the ITS region sequences of Mesorhizobium ciceri LMG $14989^{\mathrm{T}}$ and Mesorhizobium loti LMG $6125^{\mathrm{T}}$ was consistent with the results of $16 \mathrm{~S}$ rRNA 
gene sequence analysis (Tan et al., 1997) and high DNADNA hybridization ( $44 \%$ ) between these strains (Nour et al., 1994).

For phylogenetic analysis of Sinorhizobium and related strains, the 16S rRNA gene sequences for nine type strains and one Korean isolate were used. For the ITS region sequences, seven type strains, one reference strain and one Korean isolate were used. The similarities of the 16S rRNA gene and ITS region sequences were over $97 \cdot 1$ and $45 \cdot 7 \%$, respectively. According to the $16 \mathrm{~S}$ rRNA dendrogram, one Korean isolate, Mes-2, was closely related to Sinorhizobium meliloti LMG $6133^{\mathrm{T}}$ (Fig. 2). Based on ITS region sequences, the Sinorhizobium strains were divided into two clear clades with relatively high bootstrap values. Mes-2 formed one clade with S. meliloti LMG $6133^{\mathrm{T}}$, Sinorhizobium medicae LMG 18864, Sinorhizobium fredii LMG $6217^{\mathrm{T}}$ and Sinorhizobium xinjiangense LMG $17930^{\mathrm{T}}$. Another clade included Sinorhizobium arboris LMG $14919^{\mathrm{T}}$ and two clones of S. kostiense LMG $19227^{\mathrm{T}}$ (data not shown). The close similarity between $S$. fredii LMG $6217^{\mathrm{T}}$ and $S$. xinjiangense LMG $17930^{\mathrm{T}}$, previously noted on the basis of $16 \mathrm{~S}$ rRNA gene sequence similarity of $99 \cdot 8 \%$ (Tan et al., 1997), was also confirmed by the ITS region sequence similarity $(94 \cdot 9 \%)$.

Phylogenetic analysis of the Korean legume isolates on the basis of $16 \mathrm{~S}$ rRNA gene and ITS region sequences showed their remarkable heterogeneity. To clarify the exact taxonomic positions of these isolates, more taxonomic methods, including other genetic methods and DNA-DNA hybridization, will be needed.

\section{REFERENCES}

Brosius, J., Palmer, M. L., Kennedy, P. J. \& Noller, H. F. (1978). Complete nucleotide sequence of a $16 \mathrm{~S}$ ribosomal RNA gene from Escherichia coli. Proc Natl Acad Sci U S A 75, 4801-4805.

Chen, W. X., Yan, G. H. \& Li, J. L. (1988). Numerical taxonomic study of fast-growing soybean rhizobia and a proposal that Rhizobium fredii be assigned to Sinorhizobium gen. nov. Int J Syst Bacteriol 38, 392-397.

Chun, J., Huq, A. \& Colwell, R. R. (1999). Analysis of 16S-23S rRNA intergenic spacer regions of Vibrio cholerae and Vibrio mimicus. Appl Environ Microbiol 65, 2202-2208.

de Lajudie, P., Willems, A., Pot, B. \& 7 other authors (1994). Polyphasic taxonomy of rhizobia: emendation of the genus Sinorhizobium and description of Sinorhizobium meliloti comb. nov., Sinorhizobium saheli sp. nov., Sinorhizobium teranga sp. nov. Int J Syst Bacteriol 44, 715-733.

de Lajudie, P., Laurent-Fulele, E., Willems, A., Torck, U., Coopman, R., Collins, M. D., Kersters, K., Dreyfus, B. \& Gillis, M. (1998). Allorhizobium undicola gen. nov., sp. nov., nitrogen-fixing bacteria that efficiently nodulate Neptunia natans in Senegal. Int J Syst Bacteriol 48, 1277-1290.
Gürtler, V. \& Stanisich, V. A. (1996). New approaches to typing and identification of bacteria using the 16S-23S rDNA spacer region. Microbiology 142, 3-16.

Jarvis, B. D. W., van Berkum, P., Chen, W. X., Nour, S. M., Fernandez, M. P., Cleyet-Marel, J. C. \& Gillis, M. (1997). Transfer of Rhizobium loti, Rhizobium huakuii, Rhizobium ciceri, Rhizobium mediterraneum, and Rhizobium tianshanense to Mesorhizobium gen. nov. Int J Syst Bacteriol 47, 895-898.

Jordan, D. C. (1984). Family III Rhizobiaceae. In Bergey's Manual of Systematic Bacteriology, vol. 1, pp. 234-244. Edited by N. R. Krieg \& J. G. Holt. Baltimore: William \& Wilkins.

Jukes, T. H. \& Cantor, C. R. (1969). Evolution of protein molecules. In Mammalian Protein Metabolism, vol. 3, pp. 21-132. Edited by H. N. Munro. New York: Academic Press.

Nakagawa, T., Shimada, M., Mukai, H., Asada, K., Kato, I., Fujino, K. \& Sato, T. (1994). Detection of alcohol-tolerant hiochi bacteria by PCR. Appl Environ Microbiol 60, 637-640.

Nour, S. M., Fernandez, M. P., Normand, P. \& Cleyet-Marel, J.-C. (1994). Rhizobium ciceri sp. nov., consisting of strains that nodulate chickpeas (Cicer arietinum L.). Int J Syst Bacteriol 44, 511-522.

Saitou, N. \& Nei, M. (1987). The neighbor-joining method: a new method for reconstructing phylogenetic trees. Mol Biol Evol 4, 406-425.

Sambrook, J., Fritsch, E. F. \& Maniatis, T. (1989). Molecular Cloning: a Laboratory Manual, 2nd edn. Cold Spring Harbor, NY: Cold Spring Harbor Laboratory.

Tan, Z. U., Xu, X. D., Wang, E. T., Gao, J. L., Martinez-Romero, E. $\&$ Chen, W. X. (1997). Phylogenetic and genetic relationships of Mesorhizobium tianshanense and related rhizobia. Int J Syst Bacteriol 47, 874-879.

van Berkum, P. \& Fuhrmann, J. J. (2000). Evolutionary relationships among the soybean bradyrhizobia reconstructed from 16S rRNA gene and internally transcribed spacer region sequence divergence. Int J Syst Evol Microbiol 50, 2165-2172.

Vincent, J. M. (1970). A manual for the practical study of rootnodule bacteria. In International Biological Programme Handbook, pp. 73-97. Oxford: Blackwell Scientific Publications.

Weisburg, W. G., Barns, S. M., Pelletier, D. A. \& Lane, D. J. (1991). 16 S ribosomal DNA amplification for phylogenetic study. J Bacteriol 173, 697-703.

Willems, A., Coopman, R. \& Gillis, M. (2001a). Phylogenetic and DNA-DNA hybridization analyses of Bradyrhizobium species. Int J Syst Evol Microbiol 51, 111-117.

Willems, A., Coopman, R. \& Gillis, M. (2001b). Comparison of sequence analysis of 16S-23S rDNA spacer regions, AFLP analysis and DNA-DNA hybridizations in Bradyrhizobium. Int J Syst Evol Microbiol 51, 623-632.

Willems, A., Doignon-Bourcier, F., Goris, J., Coopman, R., de Lajudie, P., De Vos, P. \& Gillis, M. (2001c). DNA-DNA hybridization study of Bradyrhizobium strains. Int J Syst Evol Microbiol 51, 1315-1322.

Young, J. M., Kuykendall, L. D., Martínez-Romero, E., Kerr, A. \& Sawada, H. (2001). A revision of Rhizobium Frank 1889, with an emended description of the genus, and the inclusion of all species of Agrobacterium Conn 1942 and Allorhizobium undicola de Lajudie et al. 1998 as new combinations: Rhizobium radiobacter, R. rhizogenes, R. rubi, R. undicola and R. vitis. Int J Syst Evol Microbiol 51, 89-103. 